\title{
Editorial
}

\section{Evolving technological change in pork production supporting expectations of improved productivity, sustainability and flexibility}

\author{
J. F. Patience ${ }^{1 \dagger}$ and J. R. Pluske ${ }^{2} \odot$ \\ ${ }^{1}$ Department of Animal Science, lowa State University, Ames, IA 50011-1178, USA; ${ }^{2}$ Agricultural Sciences, Murdoch University, Murdoch, WA 6150, Australia
}

The Australasian Pig Science Association (APSA) has a long and storied history of helping to lead thoughtful discussion on important topics affecting pork production. Established in 1987, it has hosted the Manipulating Pig Production conference every 2 years, with the 2019 meeting the 17th such event. This conference is viewed globally as an innovative and progressive event. In this regard, the global pork industry is working hard to respond to the many forces affecting its future: management and prevention of diseases, including the debilitating viral disease African swine fever (Sanchez-Cordon et al., 2018), improving productivity to fulfil expectations of demand for product, attention to pork's environmental footprint and satisfying an increasingly demanding and diverse consumer marketplace (Busch and Spiller, 2019). A special issue of Animal, including many topics seeking to address the aforementioned issues, is therefore appropriate and timely. The content of this special issue, reflected in its diversity, reveals some of the approaches that are being brought to bear to address these challenges, from precision agriculture to alternative protein sources to improved control of reproduction.

The industry's interest in new technology is perfectly revealed in the report by Boyd et al. (2019). They identify innovations which have altered the very trajectory of the industry in North America, and probably globally; this includes the adoption of the tools of molecular genetics to accelerate genetic improvement, molecular-based tools to improve disease diagnosis and control and the tools of near-infrared spectroscopy (NIRS) to improve the precision of feed production (Bjustrom-Kraft et al., 2018; Faba et al., 2019). Some of these advances have truly been gamechangers to pork production, but some newer developments may prove to be of equal or greater importance in the future.

One of these developments is precision production ('precision agriculture'), something which agronomists have embraced effectively and now consider it a routine part of their decision-making process. It is now becoming an

\footnotetext{
${ }^{\dagger}$ E-mail: jfp@iastate.edu
}

increasingly important part of animal agriculture (Liebe and White, 2019). Norton (2019) explains that a critical step to improving the precision of pork production is the development and implementation of sound and image analysis to monitor individual pigs. With this ability in place, it will be possible to integrate more robust information which in turn will lead to improved decisions on feeding, housing and management. There are other means of achieving precision in the overall pork production system; NIRS is one of those tools and, as presented by Piotrowski et al. (2019), can be used to achieve accuracy in a very specific but nonetheless important aspect of pork production, namely pork carcass and meat quality.

Feed remains the largest single expense in pork production; hence addressing means to optimise its use is always of interest and importance. Tokach et al. (2019) provide an extensive review of the recent literature addressing optimised feeding of the hyper-prolific sow. As the authors emphasise, there are two main phases to consider: the periparturient period followed by actual lactation. The former is focused on success in farrowing, expressed by improved birth weights, reduced stillbirths and improved colostrum quantity and quality. The emphasis on feeding the sow during lactation is maximising milk production combined with maintaining body condition in the sow, especially in order to achieve success in re-breeding for the subsequent parity (Theil, 2015).

In interrelated research, Bagnell and Bartol (2019) discuss how maternal programming impacts not just pre-weaning performance but also the adult phenotype. They further present evidence for the lactocrine hypothesis, a mechanism mediated by milk-borne bioactive factors which serve as a vehicle of communication between the dam and her offspring shortly after farrowing. In the end, Tokach et al. (2019) and Bagnell and Bartol (2019) both agree on the importance of the periparturient period. Gaining knowledge and improving feeding management around the time of, and shortly after, farrowing could be the key to considerable improvement in 
sow reproductive performance and even post-weaning phenotype (Tokach and Dial, 1992).

Optimising feed costs implies an understanding of ingredient availability, use and cost. A growing area of interest worldwide is the use of insect meal in pig diets, which is reviewed by DiGiacomo et al. (2019). The amino acid profile of black solider fly larvae is surprisingly similar to that of soybean meal, laying the foundation for potential successful use. Initial feeding trials with pigs have proven encouraging, but questions remain regarding palatability, nutrient supply and meat quality. One of the characteristics of insect meal is its high fat content, which is a positive with respect to energy intake but may adversely impact ultimate meat quality and feed intake.

While insect meal is being considered for use in pig diets, alternative proteins are also being investigated for human consumption. Warner (2019) provides an interesting overview of cell-based meat and the challenges faced by developers seeking to find a spot in the consumer marketplace. As with many new technologies, cost is a considerable barrier to adoption, but progress is being rapidly made. The greatest competition to cell-based meat may not be the real thing, but rather rapid developments in plant-based products which have also experienced considerable progress in taste and texture. Regulatory and labelling requirements may also be a barrier to finding a place on restaurant menus or grocery shelves.

Water is a conundrum in pig nutrition. It is critical to life and must be provided in sufficient quantity and quality to the pig, but clarity on what this means is elusive (Patience, 2013). Little et al. (2019) tackle a related topic, namely the use of water as a vehicle by which medications can be provided to pigs at therapeutic levels. This is a topic of growing importance since there is a widespread desire to reduce the delivery of medication via the feed, and water seems to be a logical alternative. However, the authors express caution due to the very real challenges of delivering the right dose of medication to the full population of pigs. Their data suggest that overor under-dosing of medications is a real concern that must be addressed.

Control of reproduction remains a topic of active consideration. The issue is not so much one of litter size, but rather control of the initiation and maintenance of reproductive cycles. Lents (2019) reviewed the literature on kisspeptin, a neuropeptide involved in the hypothalamicpituitary axis and therefore involved in the regulation of gonadotropins and reproduction. Research in swine, as opposed to some other species, has lagged, and the author presents his argument for more attention to this important topic in the future.

Finally, Hutchinson and Terry (2019) take us further afield into territory unfamiliar to many, but perhaps regrettably so. Progress in understanding the connection between the brain and the cells of the immune system is revealing great opportunities in human medicine, especially psychiatry. Similar progress in swine is further down the road, reasons for which are enunciated by the authors.
In summary, the reader can see that APSA has once again developed an outstanding scientific programme for its biennial Manipulating Pig Production conference that covers a diverse array of topics highly relevant to the modern pork industry. Meetings of this nature, and associated special issues of the journal, will help to encourage further developments in new technologies, improvements in existing technologies and expanded collaborations in the future.

\section{Acknowledgements}

A special word of thanks is due to the members of the APSA Committee (Rebecca Athorn, Charles Rikard-Bell, Frank Dunshea, Robert Hewitt, Pat Mitchell, Cameron Ralph, Robyn Terry, Stuart Wilkinson (President)) who generously gave of their time in organising the speakers and this conference, chairing the scientific sessions and assistance with reviewing. Sincere thanks are also due to the APSA executive manager, Emalyn Loudon, for her enthusiasm and help in organisation of the scientific meeting.

(1) J. R. Pluske 0000-0002-7194-2164

\section{Declaration of interest}

John Pluske is a member of the APSA Committee.

\section{Ethics statement}

Not applicable.

\section{Software and data repository resources}

Not applicable.

\section{References}

Bagnell CA and Bartol FF 2019. Review: Maternal programming of development in the pig and the lactocrine hypothesis. Animal, this issue.

Bjustrom-Kraft J, Christopher-Hennings J, Daly R, Main R, Torrison J, Thurn M and Zimmerman J 2018. The use of oral fluid diagnostics in swine medicine. Journal of Swine Health and Production 26, 262-269.

Boyd RD, Zier-Rush CE, Moeser AJ, Culbertson M, Stewart KR, Rosero DS and Patience JF 2019. Innovation through research in the North American pork industry. Animal, this issue.

Busch $G$ and Spiller A 2019. Consumer acceptance of livestock farming around the globe. Animal Frontiers 8, 1-3.

DiGiacomo K, DiGiacomo K and Leury BJ 2019. Review: Insect meal - a future source of protein feed for pigs? Animal, this issue.

Faba L, Sola-Oriol D, Balfagon A, Coma J and Gasa J 2019, Assessing the effect of ingredients variability on the composition of the final complete feed for swine. Canadian Journal of Animal Science 99, 7-14.

Hutchinson MR and Terry R 2019. Review: What innovations in pain measurement and control might be possible if we could quantify the neuroimmune synapse? Animal, this issue.

Lents CA 2019. Review: Kisspeptin and reproduction in the pig. Animal, this issue.

Liebe DM and White RR 2019. Analytics in sustainable precision animal agriculture. Animal Frontiers 9, 16-24.

Little SB, Crabb HK, Woodward AP, Browning GF and Billamn-Jacobe H 2019. Review: Water medication of growing pigs - sources of between-animal variability in systemic exposure to antimicrobials. Animal, this issue. 


\section{Patience and Pluske}

Norton T 2019. Automated monitoring of livestock for sustainable production: a review of developments and implementations. Animal, this issue.

Patience JF 2013. Water in swine nutrition. In Sustainable swine nutrition (ed. LL Chiba), pp. 3-22. John Wiley \& Son, Inc., Hoboken, NJ, USA.

Piotrowski C, Garcia R, Garrido-Varo A, Perez-Marin D, Riccioli C and Fearn T 2019. Short communication on the potential of Portable Near Infrared spectroscopy for assuring quality and authenticity in the food chain. Animal, this issue.

Sanchez-Cordon PJ, Montoya M, Reis AL and Dixon LK 2018. African swine fever: a re-emerging viral disease threatening the global pig industry. The Veterinary Journal 233, 41-48.
Theil PK 2015. Transition feeding of sows. In The gestating and lactating sow (ed. C Farmer), pp. 147-172. Wageningen Academic Publishers, Wageningen The Netherlands.

Tokach MD and Dial GD 1992. Managing the lactating sow for optimal weaning and rebreeding performance. Veterinary Clinics of North America: Food Animal Practice 8, 559-573.

Tokach MD, Menegat MB, Gourley KM and Goodband RD 2019. Review: Nutrient requirements of the modern high-producing lactating sow, with an emphasis on amino acid requirements. Animal, this issue.

Warner RD 2019. Review: Analysis of the process and drivers for cellular meat production. Animal, this issue. 